\title{
To Evalute the Effectiveness of Structured Demonstation Programme on Cardiopulmonary Resuscitation in Bsc Nursing $3^{\text {rd }}$ year Students
}

\author{
Ms Sapana Gupta* Ms Indu Kumari**Ms Itu Roy***Ms Sasmita Nayak**** \\ Ms Lopamudra Mishra***** Mrs Minati Das****** \\ KINS College of Nursing, KIIT University, Bhubaneswar, Odisha, India $4^{\text {th }}$ Year Bsc Nursing Student, Lecturer \\ of College of Nursing
}

\begin{abstract}
Cardiovascular disease is the world's leading killer. According to world Health Organization (WHO) estimates, 16.7 million people around the globe, die of cardiovascular disease each year. This is over $29 \%$ of all deaths globally. In India 9 crore Indian suffer from heart disease and $30 \%$ more are at risk high risk. Sudden cardiac death is a major cause of death in today's developed countries .During this time victims can rely upon CPR provided by educated bystanders and CPR may positively influence short and long-term survival of cardiac arrest victims without the use of drugs or specialist equipment. A structured knowledge questionnaire was prepared for the assessment of skill. Pre test was done on $1^{\text {st }}$ day and planned demonstration programme was given on same day. On day $7^{\text {th }}$ post test was done with same questionnaire.post test demonstration skill score was more than pre test demonstration skill score knowledge. Pre test-Mean 8.8, mean\%29.3\%, SD-17.8 and post test-Mean-13.6,mean\%-45.3\%,SD-20.5." $t$ " value was 2.49 which is greater than the tabulated value at ( $p=0.05$ is 2.05)level of significance and which highly significant. The study concludes that structured demonstration programme is effective in improving the skills of students related to cardiopulmonary resuscitation.
\end{abstract}

Keywords: cardiopulmonary resuscitation, cardiac arrest, structured demonstration programme

\section{Introduction}

According To WHO, Heart disease is the world's largest killer claiming 17.5 million lives every year. About every 29 seconds, an Indian dies of heart problem. As many as 20,000 new heart patients develop every day. In India 9 crore Indian suffer from heart disease and 30\% more are at high risk. Sudden Cardiac arrest is a major public health problem. Cardiopulmonary resuscitation (CPR) is the provision of treatment designed to maintain adequate circulation and ventilation to the patient in cardiac arrest, without the use of drugs on specialist equipment.

\subsection{Background of the study}

According to Hamilton R, BLS is the fundamental technique for the emergency treatment of Cardiac arrest. The standard training of Cardio pulmonary resuscitation has been emphasized more than ever. Common people in developed countries have received popular education of CPR programme of BLS training. CPR and BLS training is mandatory for student nurses and is important as nurses often first discover the victims of cardiac arrest in hospital.

\subsection{Purpose}

Education change is necessary to meet the demands of current health care environment. Learning objectives should focus on the best practice outcome and should emphasize what the health care provider is expected to do after the educational activity is over. Regulating agencies and consumer hold health care personnel accountable for high quality, safe patient care. Educational activities should provide the skill and knowledge that enable nurse to meet this goal. The new nursing generation needs to grow in proper and time provision of essential care to their patients. For that, nursing student need necessary knowledge and skill by repeated training and practice.

\subsection{Objectives}

1. To assess the knowledge regarding cardio pulmonary resuscitation before administrating structured demonstration programme among $3^{\text {rd }}$ year B.Sc. Nursing students.

2. To develops and administering structured demonstration programme (SDP) to $3^{\text {rd }}$ year B.Sc. Nursing students in KINS regarding cardiopulmonary resuscitation. 
3. To assess the skill of $3^{\text {rd }}$ year B.Sc. Nursing students regarding cardio pulmonary resuscitation after administering SDP in KINS.

4. To evaluate the effectiveness of SDP regarding cardio pulmonary resuscitation among $3^{\text {rd }}$ year B.Sc. Nursing students in KINS.

\section{Methodology}

The research design was one group pre test and post test pre-experimental design with evaluative research approach Study was conducted in nursing College KINS, KIIT University, Bhubaneswar, Odisha in 2016. The study population was the $3^{\text {rd }}$ year Bsc Nursing Student and simple random sampling technique was used for the study and 30 sample sizes was collected .Ethical consideration taken from KINS College of nursing principal and informed consent was taken from $3^{\text {rd }}$ year Bsc Nursing student. A close ended structured demonstration programme used to assess skill and question subdivided into two sections; related to socio demographic variable and skill regarding cardiopulmonary resuscitation.

Pretest was conducted on 1st day and structured demonstration programme on CPR provided to the student on same day .After 7days post test was conducted.

\section{Result}

The Line shows that, the line of the post test scores lies to the right of the pretest score over the entire range, showing that the posttest score are the consistently higher than the posttest score.

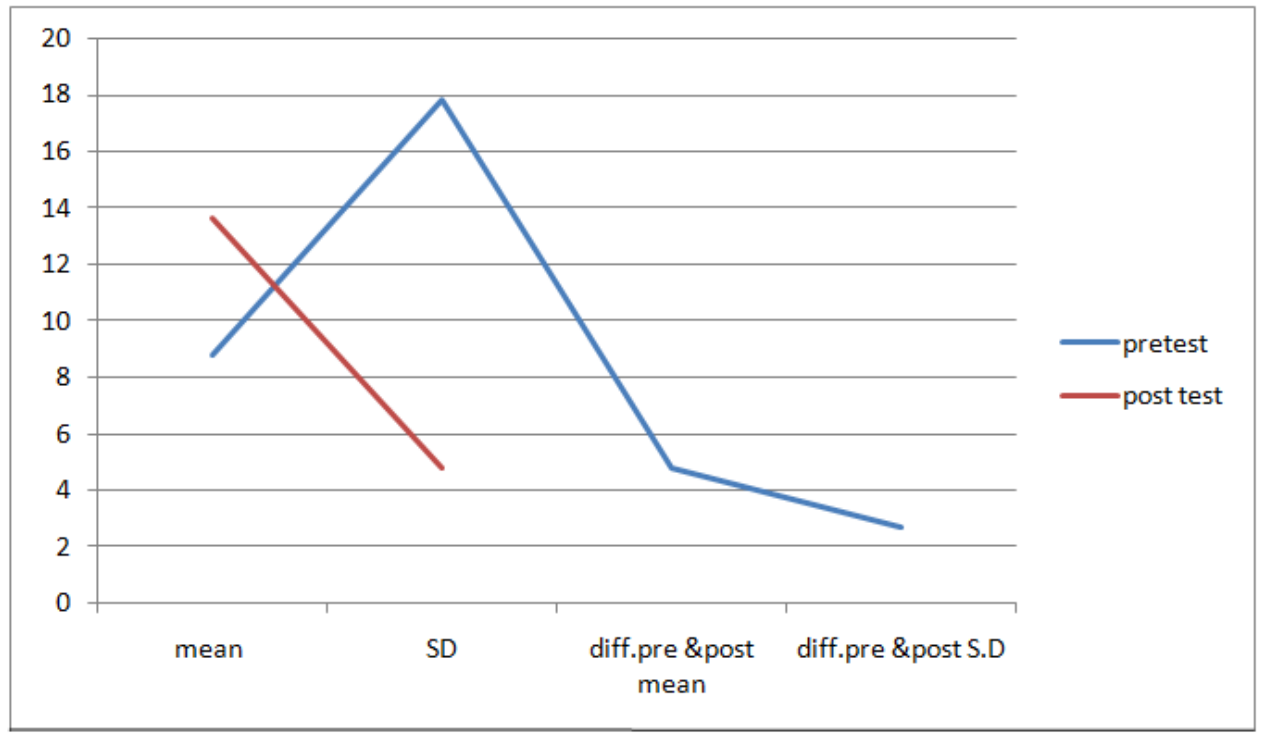

Comparison of pre and post test of CPR

\begin{tabular}{|l|l|l|l|l|c|}
\hline \multicolumn{1}{|c|}{ Test } & \multicolumn{1}{|c|}{$\mathrm{N}$} & \multicolumn{1}{|c|}{ Mean } & \multicolumn{1}{|c|}{ S.D } & $\begin{array}{l}\text { Difference of pre and } \\
\text { post mean }\end{array}$ & $\begin{array}{l}\text { Difference of pre and } \\
\text { post S.D }\end{array}$ \\
\hline Pre-test & 30 & 8.8 & 17.8 & 4.8 & 2.7 \\
\hline Post-test & 30 & 13.6 & 20.5 & & \\
\hline
\end{tabular}

The above Table No.1 shows the comparison of pre-test and post-test mean is 4.8 and comparision of pre-test and post-test S.D is 2.7 among B.Sc Nursing $3^{\text {rd }}$ year students. From the above Table No.1 and line diagram - shows the distribution of level of skill i.e. Good (66\%-85\%), Average (46\%-65\%) and Poor (26\%$45 \%)$ and their frequencies are $24,4 \& 2$ respectively. The percentage of Good is $76 \%$, Average is $13 \%$ and Poor is $6 \%$. The data reveals that the maximum number of frequency and percentage is of Good i.e. $24(76 \%)$.The mean value of posttest is 13.6 , its mean percentage is $45.3 \%$ and S.D is 20.5 The tabulated value at $\mathrm{P}=0.05$ is 2.05 . The calculated $\mathbf{t}$-value was found 2.49 which is greater than above tabulated value.

\section{Conclusion}

The present study showed that the skill among the B.Sc Nursing $3^{\text {rd }}$ year students regarding CPR in them of mean\% was $16 \%$. The comparison of pre-post test and post test regarding CPR shows that students had gained some skill after administrating structured demonstration programme on CPR with mean\% 45.3 of post test. 


\section{References}

[1]. Acheson A, Brown, Bhutani VK et al. The Effect of By-Stander CPR on Survival of Out-Of-Hospital Cardiac Arrest Victims. Am Heart J 1985; 932-937.

[2]. Brendan Docherty. Basic Life Support and AED. Clinical Manager Cardiology and Critical Care. 2003 , August: 56-59.

[3]. Wik L, Steen PA, Bircher NG. Quality Of Bystander Cardiopulmonary Resuscitation Influences Outcome After Pre hospital Cardiac Arrest. Resuscitation 1994; 28: 195-203.

[4]. Cardiopulmonary resuscitation: statement by the Ad Hoc Committee ,Cardiopulmonary Resuscitation of the Division of Medical Sciences, National Academy of Sciences, National Research Council. Cardiopulmonary Resuscitation. JAMA1966; 198:372,379.Availablefrom,http://www.expresshealthcaremgmt.com/20041215/criticare06.shtml.

[5]. World Health Organization Statistical Information System (WHOSIS). Cardiovascular Disease Statistics. 2009. Available From,. http://www3.who.int/whosis/menu.cfm

[6]. Asian Journal of Nursing Education And Research (AJNER) Volume 02,Issueo1,March2012.AvailableFrom, http;/www. anvpublication.org/ajner.htm.

[7]. Hamilton R, Assessment of Knowledge and Skill Retention Following Cardio Pulmonary Resuscitation Training, new ham university hospital NHS trust, Calcutta. Aug 2005; 288-955.

[8]. Rebecca. A quasi-experimental research to investigate the retention of basic cardiopulmonary resuscitation skills and knowledge by qualified nurses following a course in professional development. Journal of Advanced Nursing. 1996, 23(5); 1016-1023. 